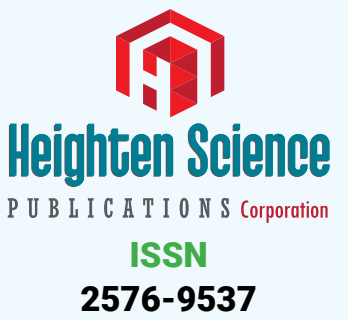

*Address for Correspondence: Dr. Cesar Raul Aguilar Garcia, General Hospital from Zone 197, Benito Bustamante w/n Col. Niños Heroes, Texcoco de Mora, Edo. Mexico, Tel: 52+ 5528550276; Email: miymc2010@hotmail.com

Submitted: 17 July 2017

Approved: 03 August 2017

Published: 04 August 2017

Copyright: @ 2017 Garcia CRA, et al. This is an open access article distributed under the Creative Commons Attribution License which permits unrestricted use, distribution, and reproduction in any medium, provided the original work is properly cited.

Keywords: Orthodeoxia; Hepatic Deficiency; Pulmonary vasodilatation

\section{Use of Orthodeoxia by pulse Oximetry in the detection of Hepatopulmonary Syndrome}

\author{
Cesar Raul Aguilar Garcia1* and Guadalupe Viridiana Ontiveros \\ Guerra $^{2}$ \\ 'Intern Medicine and Intensive Therapy, General Hospital, Zone 197-Mexican Institute of Social \\ Insurance, Intern Medicine Service, Puebla University Hospital, Mexico \\ ${ }^{2}$ General Medicine, Opportune Detection Unit of Health, Mexico City Health Secretary Ship, \\ Mexico
}

\title{
ABSTRACT
}

Chronic Hepatic deficiency due to the ingestion of alcohol remains as one of the main causes of morbidity and mortality in our country. From it a variety of complications arise, one of them is the Hepatopulmonary Syndrome, which usually goes unnoticed and undiagnosed; this syndrome is distinguished by the presence of hypoxemia and pulmonary vasodilation. The gold standard to establish a diagnostic is contrast-enhanced Echocardiogram. No pathognomonic sign is known for this syndrome, which leads the present elaboration to evaluate the use of orthodeoxia by pulse oximetry as a screening test in the detection of Hepatopulmonary Syndrome cases.

\section{BACKGROUND}

The development of Hepatopulmonary Syndrome (HPS) is independent to the etiology of the hepatic illness; however more studies associate it with hepatic cirrhosis and portal hypertension. This syndrome is currently defined by the presence of this trio: a) hepatic illness, b) hypoxemia $(\mathrm{PaO} 2<60 \mathrm{mmHgand}$ difference alveolar-arterial $>15 \mathrm{mmHg}$ ) and c) pulmonary vasodilatation $[1,2]$. Within the physiopathology of this syndrome we can find three main mechanisms for the hypoxia: pulmonary right to left shunts, faults in the capillary socket diffusion of oxygen and alterations in the alveolar perfusion-ventilation [3]. This happens due to the pulmonary vasodilatation causing widened capillary diameter and in consecuence, the blood is not oxygenated enough.

Also, during the development of Hepatopulmonary Syndrome there's a series of alterations related to the hepatic injury, which gives place to the production or liberation of mediators in the venous circulation, being the main alteration, the increase of nitric oxide [4].

It is known that in early stages, the Hepatopulmonary Syndrome patient remains asymptomatic. Until now, no pathognomonic symptoms or signs exist for this syndrome. The signs and symptoms are divided into: hepatic and hypoxic. Hepatic ones include jaundice, telangiectasias, hepatomegaly, ascites, collateral circulation, and extremity edema; and within the hypoxic are: exertional dypnea, platypnea, digital clubbing, cyanosis and orthodeoxia (to the physical examination) [5,6]. Hepatopulmonary Syndrome should be suspected in patients with chronic hepatic damage that count with hypoxemia, that is to say PO2 lower than $60 \mathrm{mmHg}$, and that show some of the symptoms already mentioned, and in the face of clinic suspicion the following must be performed: 
Arterial Gasometry: in this test hypoxemia can be found, the $\mathrm{PaO} 2$ is lower than 60 $\mathrm{mmHg}$ to atmosphere air, and desaturation could present itself in more than $10 \mathrm{mmHg}$ in upright position. (Orthodeoxia).

Respiratory Function Tests: they show a restrictive pattern, decrease of the utter pulmonary capacity, decrease in the diffusion capacity, widening of the gradient arterial-alveolus and in further studies airflow obstruction can be observed.

Echocardiogram: this is the most sensitive and specific test for diagnosing Hepatopulmonary Syndrome, it a contrast-enhanced echocardiogram. The microbubbles that are injected at the right atrium level, in normal conditions, shouldn't be noticeable in the left circulation because they are trapped in the pulmonary circulation. Nevertheless, when anomalous arteriovenous communications exists the microbubbles go through the left atrium six heartbeats after the injection, giving this test positive for the diagnostic of Hepatopulmonary Syndrome. In this study, the presence of intracardiac shunts can also be corroborated, because in case the microbubbles exist they can be observed in the left cavities in the first three heartbeats.

Scintigraphy: it's used to confirm the presence of pulmonary vascular dilatations making use of albumin macro aggregates marked with technetium-99m. This allows the quantification of the percentage of intrapulmonary dilatations based on a higher extrapulmonary perception of the macro aggregates. It is consired pathological when the values are $\geq 6 \%$.

Angiography: is an invasive test, however it is useful to locate and value the vascular dilatations and the arteriovenous communications properly.

Among other studies there's the TAC single chest chamber, however it's specificity and sensibility are low, for this reason its utilization would be indicated more to discard any respiratory etiology that may be causing hypoxemia [7-11].

Within the treatment, in some bibliographies, supplementary oxygen and hepatic transplant are mentioned as the only satisfactory answer. Currently, studies exist which include pentoxifylline, norfloxacin, nitric oxide and methylene blue, each one according to the Hepatopulmonary Syndrome physiopathology, nonetheless, no study has been conclusive [12-14].

\section{OBJECTIVE}

The clinical picture of the Hepatopulmonary Syndrome is insidious and is not counted as a pathological sign, which causes a low index of suspicion and belated diagnostics. This is why there's so much determination to the orthodeoxia as a proposed index for the opportune detection of Hepatopulmonary Syndrome to be later corroborated with more extensive studies.

\section{MATERIAL AND METHODS}

A descriptive study was taken place, transversal, not experimental, on 15 admitted patients in the Internal Medicine Service at the University Hospital of the Meritorious Autonomous University of Puebla in a lapse of one year, which fulfilled the inclusion standards previously established. A data collection paper was designed on which information was collected with the study variables:

- Age

- Gender

- Child-Pugh classification,

- Time of evolution in the ingestion of alcohol 
Income diagnostics, results of the following studies: chest radiography, electrocardiogram, spirometry, arterial blood gas analysis, abdominal ultrasound, endoscopy, orthodeoxia test, contrast echocardiogram, presence of telangiectasia and digital clubbing. Once the patients have been admitted they are staged according to the Child Pugh classification, serology was performed for Hepatitis B and C virus so these could be discarded. The data was captured and was later statistically analyzed in the EPI Info program, version 6.04 C of the CDC from Atlanta, USA.

There were 15 patients included, of which $53.3 \%$ were male and $46.7 \%$ were female, the age range was of 46 to 80 years old, with an average of 60.33 years old and a standard variation of 11.65 . The Child-Pugh classification distribution was: a $7.2 \%$ classification A, $46.4 \%$ for classification B, and a $46.4 \%$ for classification C; making the last two equal. In this study, the alcohol ingestion average was 25.4 years with a standard variation of 12.5 years.

The chest X-ray was normal in $100 \%$ of the patients, electrocardiogram, was a $93.3 \%$ without any alterations, spirometry was normal in $93.3 \%$, the blood gas alterations found were metabolic acidosis, $6.7 \%$, and respiratory alkalosis, $93.3 \%$, in the group of patients $26.6 \%$ presented hypoxemia among with respiratory alkalosis. The abdominal echography was normal in $86.27 \%$ and there were abnormalities in $13.8 \%$, with the presence of ascites.

The esophageal varicose veins by endoscopy frequency was $73.3 \%$, congestive gastritis was a $53.3 \%$ and erosive a $6.7 \%$. The orthodeoxia test was positive in 5 of the 15 patients, which equals a $33.3 \%$ of the patients. The contrast-enhanced echocardiogram was positive for pulmonary vasodilatation in 4 out of 5 patients, which equals $26.7 \%$ (Table 1).

The main diagnoses by Echocardiography are listed in table 2 .

\section{DISCUSSION}

Platypnea and orthodeoxia defined as dyspnea and deterioration in the arterial oxygenation respectively included by orthostatism are extremely common in this syndrome and present themselves in up to a $70 \%$ of the patients, primarily orthodeoxia suggests the diagnose. Although it was a very short study with a small amount of patients, the purpose was to establish orthodeoxia as a screening test for the detection of Hepatopulmonary Syndrome. In the present elaboration, there was an interrelation in 4 of the 15 patients with a positive orthodeoxia test result and contrast-enhanced echocardiogram with pulmonary vasodilatation. The pathophysiological disorder in founded in a ventilation/perfusion fault due to the important pulmonary vasodilatation (pulmonary capillary of 30-50 $\mathrm{mm}$, normal of 8-15 $\mathrm{mm}$ ) because the oxygen molecules can't reach the central part of the blood flow that overpasses the capillary. Due to the predominance of the pulmonaryvasodilatation in the middleand lower lobes, hypoxemia

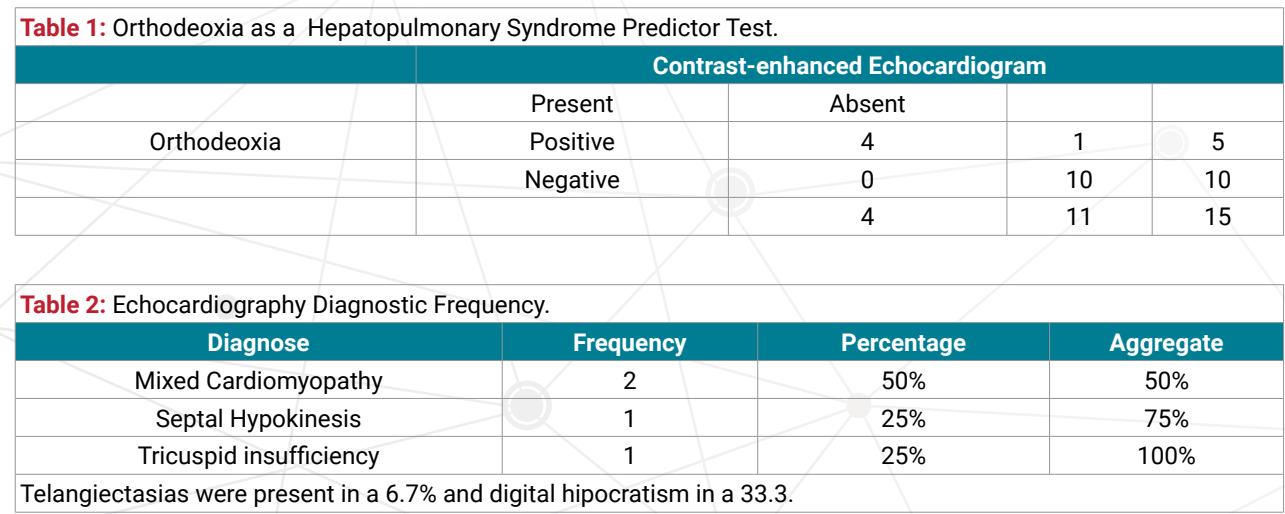


and dyspnea are emphasized with the orthostatism and improve with the decubitus, in this way founding the orthodeoxia test. Thirteen of the fifteen patients presented respiratory alkalosis due to the ventilation perfusion disorder which stimulates an increase in the respiratory frequency and consequently hyperventilation, hypocapnia and respiratory alkalosis and hypoxemia. The Hepatopulmonary Syndrome is a wrong prognostic indicator, once diagnosed $40 \%$ of patients decease in 2.5 average/years, cause of other complications of the Hepatic Deficiency. Pulse oximetry was used in the detection of Hepatopulmonary Syndrome as a non-invasive, easy-to-use, practical, reproducible screening test that can be performed at the patient's head, which is subsequently corroborated by arterial blood gas analysis.

\section{CONCLUSIONS}

We found an interesting finding in the interrelation of orthodeoxia and contrastenhanced echocardiogram, so now the patients detected with the syndrome must be summited to more extensive studies to insure the sickness and take the needed therapeutic relevant measures. Nevertheless, more studies are needed to validate or not and in consequence recommend the realization of said test as a routine mode.

\section{REFERENCES}

1. Salazar-Marcelino AE, Herrera-García JC, Toledo-Estrada J, Mendoza-Torres MA, Romero- Ogawa T. Síndrome Hepatopulmonar: Situación clínica en un hospital de tercer nivel en Puebla, Mexico. Neumólogo Cir Tórax. 2016; 75: 18-24. Ref.: https://goo.gl/41PTHu

2. Nacif LS, Andraus W, Pinheiro RS, Ducatti L, Haddad LB, et al. The hepatopulmonary syndrome. Arq Bras Cir Dig. 2014; 27: 145-147. Ref.: https://goo.gl/wT8WE5

3. Muñoz JG. Síndrome hepatopulmonar. Rev Med Cos Cen. 2014; 71: 395-401. Ref.: https://goo.gl/cHUySF

4. Raevens S, Geerts A, Van Satenkiste C, Verhelest X, Van Vlerberghe H, et al. Hepatopulmonary syndrome and portopulmonary hipertensión: reventar knowtedege in pathogenesis and overview of clinical assessment. Liver Int. 2015; 35: 1646-1660. Ref.: https://goo.gl/U8xc7Q

5. Sáenz-Gómez J, Karam- Bechara J, Jamaica-Banderas L. Síndrome hepatopulmonar como causa de hipoxemia en niños con enfermedad hepática. Bol Med Hospital Infantil Mex. 2015; 72: 124-128. Ref.: https://goo.gl/yWgbdd

6. Muñoz-Maya OG, Santos OM, Granda P, Vega J, Martin Jl, et al. Síndrome hepatopulmonar en paciente con hipertensión portal no cirrotica. Reporte de caso. Rev Col Gastroenterol. 2012; 27: 323326. Ref.: https://goo.gl/1XD8DL

7. Orozco-Delgado M, López-Cantero $M$, Zampe, la V, Vicente R, Galan J. Factores predicadores de mortalidad y estrategias de detección precoz de síndrome hepatopulmonar en pacientes transpalntados hepáticos. Predictors of mortality and early detection strategies for hepatopulmonary syndrome in liver transplant patients. Rev Colombia Anestesiol. 2016; 44: 311-316. Ref.: https://goo.gl/hyFDde

8. Lyer VN, Swanson KI, Cartín CR, Dierkhising RA, Rosen CB, et al. Hepatopulmonary syndrome: favorable outcomes ni the MELD exception Era. Hepatology jun. 2013; 57: 2427-2435. Ref.: https://goo.gl/PZXk5A

9. Carrillo ER, Gonzalez SJ, Serralde ZA. Síndrome Hepatopulmonar. Rev Fac Med. 2001; 44: 207-211.

10. Navasa M, Agusti C. Síndrome Hepatopulmonar. Asociación Española de Estudios del Higado.

11. Lange PA, Stoller KJ. The Hepatopulmonary Syndrome. Ann Intern Med. 1995; 122: 521-29. Ref.: https://goo.gl/6iAwuo

12. Grace JA, Angus PW. Hepatopulmonary syndrome: update on recent advances in phatophysiology invetigation, and treatment. J Gastroenterol Hepatol. 2013; 28: 213-219. Ref.: https://goo.gl/bw9oYk

13. Rabiller A, Núñez H, Lebrec $D$, Tazl KA, Wartski M, et al. Prevention os gram-negative translocation reduces the severidad oh hepatopulmonary syndrome. Am J Respir Crit Care Med. 2002; 66: 514 517. Ref.: https://goo.gl/Yj5uhG

14. Ahad E, Amir AK, Seung KA. Pharmacologivsl treatment for hepatopulmonary syndrome. Bío Med Research International. 2013. Ref.: https://goo.gl/DbA2yB 